\title{
Bacterial communities from Arctic seasonal sea ice are more compositionally variable than those from multi-year sea ice
}

\author{
Ido Hatam $^{1}$, Benjamin Lange ${ }^{2,3,4}$, Justin Beckers ${ }^{3}$, Christian Haas ${ }^{3,5}$ and Brian Lanoil ${ }^{1}$ \\ ${ }^{1}$ Department of Biological Sciences, University of Alberta, Edmonton, Alberta, Canada; ${ }^{2}$ Alfred Wegener \\ Institute, Helmholtz Centre for Polar and Marine Research, Bremerhaven, Germany; ${ }^{3}$ Department of Earth and \\ Atmospheric Sciences, University of Alberta, Edmonton, Alberta, Canada; ${ }^{4}$ Zoological Institute and \\ Zoological Museum, Biocenter Grindel, University of Hamburg, Hamburg, Germany and ${ }^{5}$ Department of Earth \\ and Space Sciences and Engineering, York University, Toronto, Ontario, Canada
}

\begin{abstract}
Arctic sea ice can be classified into two types: seasonal ice (first-year ice, FYI) and multi-year ice (MYI). Despite striking differences in the physical and chemical characteristics of FYI and MYI, and the key role sea ice bacteria play in biogeochemical cycles of the Arctic Ocean, there are a limited number of studies comparing the bacterial communities from these two ice types. Here, we compare the membership and composition of bacterial communities from FYI and MYI sampled north of Ellesmere Island, Canada. Our results show that communities from both ice types were dominated by similar class-level phylogenetic groups. However, at the operational taxonomic unit (OTU) level, communities from MYI and FYI differed in both membership and composition. Communities from MYI sites had consistent structure, with similar membership (presence/absence) and composition (OTU abundance) independent of location and year of sample. By contrast, communities from FYI were more variable. Although FYI bacterial communities from different locations and different years shared similar membership, they varied significantly in composition. Should these findings apply to sea ice across the Arctic, we predict increased compositional variability in sea ice bacterial communities resulting from the ongoing transition from predominantly MYI to FYI, which may impact nutrient dynamics in the Arctic Ocean.

The ISME Journal (2016) 10, 2543-2552; doi:10.1038/ismej.2016.4; published online 16 February 2016
\end{abstract}

\section{Introduction}

The Arctic Ocean has a vast sea ice cover, which spans an average area of 15 million $\mathrm{km}^{2}$ at its maximal extent (Wadhams, 2000). Sea ice can be classified into two main types: (A) seasonal ice, which forms during the freeze-up period and undergoes complete melt during the spring and summer, a.k.a. first-year ice (FYI); and (B) perennial or multi-year ice (MYI), which is ice that survives at least one melt season (Wadhams, 2000). MYI is typically much thicker than FYI; especially along the northern coast of Canada and Greenland where MYI is generally thicker than $3.5 \mathrm{~m}$ (Haas et al., 2006, 2010). Until recently, MYI dominated the Arctic sea ice cover; however, the proportion of MYI has dwindled from $>70 \%$ of the total sea ice cover to under $45 \%$ over the past three decades (Serreze et al., 2007; Maslanik et al., 2011).

Correspondence: B Lanoil, Department Biological Sciences, University of Alberta, CW405 Biological Sciences Building, Edmonton, T6G2E9 Alberta, Canada.

E-mail: brian.lanoil@ualberta.ca

Received 5 July 2015; revised 8 October 2015; accepted 10 December 2015; published online 16 February 2016
Furthermore, the remaining MYI tends to be younger and therefore thinner (Maslanik et al., 2011). Thus, Arctic perennial sea ice cover is not only shrinking in extent, it is also losing volume. These trends are expected to continue and it is conservatively predicted that the Arctic Ocean will be largely ice free during summer by the end of the 21st century (Boé et al., 2009).

The loss of MYI has had a significant impact on Arctic climate and ecosystems. Larger open water areas in summer have contributed to the accelerated warming in the Arctic and to potential changes in atmospheric circulation (Overland et al., 2012). Decline in summer sea ice has severely impacted animals that are dependent on ice for feeding, dispersal and mating (see review by Post et al., 2013). Phytoplankton blooms in the Arctic Ocean are normally associated with sea ice edge and retreat areas, and are reliant on nutrient release from melting sea ice. Over the past 15 years, massive under ice phytoplankton blooms have occurred frequently underneath pack ice in the western Arctic Ocean (Arrigo et al., 2012; Lowry et al., 2014). These recent massive under ice blooms are associated with 
the increase in a much thinner FYI cover, which allows higher light penetration. Furthermore, it has been suggested that sea ice algae productivity would increase with the transition to FYI (Wassmann and Reigstad, 2011). However a recent study suggests that the productivity of thick MYI has been underestimated and that loss of MYI will not result in increased productivity in Arctic sea ice (Lange et al., 2015).

Arctic sea ice is a habitat for a diverse community of microorganisms that primarily inhabit liquid brine channels within the ice (Junge et al., 2001; Mock and Thomas, 2005). The most recognizable feature of this community is the diatom bloom in the bottom 5-10 $\mathrm{cm}$ of the ice during the spring and early summer (Gosselin et al., 1997; McMinn and Hegseth, 2007; McMinn et al., 2007). However, sea ice also hosts diverse communities of heterotrophic bacteria. Constituents of these communities are metabolically active throughout the year, and are key regulators of the spring Arctic Ocean diatom bloom through the regeneration of nutrients via the microbial loop (Poltermann, 2001; Junge et al., 2004, 2006; Deming, 2007). Moreover, during the polar winter, heterotrophic production and growth fertilizes the ice in preparation for the spring and summer bloom and supplies the ice and underlying water column with a small but stable subsidy of organic matter through secondary production (Riedel et al., 2008; Wing et al., 2012).

The physical and chemical environment in MYI and FYI is quite different and can therefore be viewed as distinct microbial habitats. The decreased thickness of FYI relative to MYI results in steeper gradients in temperature, light, brine volume and salinity in FYI, as well as increased light transmission to the underlying water (Eicken, 2008). Because of gravitational drainage of brine and flushing of the ice with freshwater from snowmelt during summer, MYI has lower brine volumes and bulk salinity and therefore has lower porosity than FYI (Wadhams, 2000; Eicken, 2008). MYI can also include layers of refrozen melt pond ice and newly formed sea ice at the bottom that are absent from FYI. These melt pond and newly formed ice layers were recently reported to host bacterial assemblages distinct from those in the older ice layers (Hatam et al., 2014). Furthermore, though MYI undergoes seasonal fluctuations in many chemical and physical parameters, it still provides a more stable habitat than FYI due to the fact that it survives for longer periods. The difference in age between MYI and FYI was speculated to be a key factor in the establishment and development of sea ice microbial community (Rysgaard and Glud, 2004).

Here, we describe the first comparative study of bacterial community structure and composition of Arctic MYI and FYI using high throughput sequencing. We found that MYI and FYI bacterial communities collected over three field seasons from the Lincoln Sea were distinct from each other and that MYI bacterial community membership and composition was less variable than for FYI bacterial communities. These results indicate that the ongoing shift from MYI to FYI will lead to shifts in the bacterial community of the Arctic Ocean and to increased variability in these communities, which potentially impact the ecosystem functions they provide.

\section{Materials and methods}

\section{Site description and sample collection}

Samples for this study were taken from ten sites; five land fast MYI sites and five adjacent land fast FYI sites located off northern Ellesmere Island, Nunavut, Canada (Supplementary Table S1). This geographical location is characterized by dominance of consolidated MYI flows with patches of first-year ice inbetween resulting from refrozen open leads. Sampling was conducted during the beginning of May 2010, 2011 and 2012. All MYI samples were collected from depressions in the ice sheet, indicating the presence of a freshwater melt pond in summer. An accurate age of the MYI was not determined; however, ice thickness ranged from 250 to $260 \mathrm{~cm}$, which is typical of MYI and thicker than most FYI (Supplementary Table S1). Furthermore, the bulk salinity profile showed low overall salinity and an increase in salinity with depth, which is characteristic of MYI (Supplementary Figure S1). FYI samples were collected from level floes identified from satellite radar images. For these sites, cores ranged in thickness from 90 to $180 \mathrm{~cm}$, which is also characteristic of FYI (Supplementary Table S1). Bulk salinity for FYI cores was higher overall than for MYI and showed the characteristic 'C'-shaped FYI salinity profile with higher salinity values at the top and bottom portions of the ice, and lower salinity in the middle (Supplementary Figure S1).

For each site, duplicate ice cores were sampled $1 \mathrm{~m}$ apart using a Kovacs Mark II 9-cm-diameter corer (Kovacs Enterprise, Roseburg, OR, USA) powered by a DeWalt $36 \mathrm{~V}$ electric hand drill (DeWalt Industrial Tool Co., Vancouver, BC, Canada). Before drilling, the core barrel was thoroughly rinsed with sterile deionized water (MilliQ Integral Water Purification System, EMD Millipore Corporation, Billerica, MA, USA). Ice cores were immediately sectioned on site at $30 \mathrm{~cm}$ intervals and placed in polypropylene bags (ULINE, Edmonton, AB, Canada). Cutting was done using a hand saw that was rinsed in deionized water and wiped with an ethanol wipe.

At four sites, additional surface sea water samples were collected (Supplementary Table S1). Duplicate 2-l water samples were pumped into polypropylene bags from the coring hole using a manual peristaltic pump (Cole Palmer, Montreal, QC, Canada). Both water and ice samples were covered, chilled and processed within $4 \mathrm{~h}$ of sampling.

\section{Sample processing}

To avoid contamination and dilution of samples, ice samples were directly thawed at room temperature in the dark, rather than isotonically (Kaartokallio et al., 2005, 2008). 
Melted ice samples and sea water samples were filtered individually through sterile $0.22 \mu \mathrm{m}$ pore size polyethersulfone membrane filters (Pall, Mississauga, ON, Canada). Between samples, glassware used for filtration and sample measurements was sterilized using $10 \%$ household bleach solution followed by thorough rinsing in sterile deionized water. Each filter was placed in a microfuge tube, submerged in RNAlater solution (Life Technologies, Burlington, ON, Canada), and stored at $-20^{\circ} \mathrm{C}$ for later DNA extraction.

\section{DNA extraction amplification and sequencing}

DNA was extracted from preserved filters by bead beating using the FastDNA SPIN Kit for Soil (MP Biomedicals, Solon, OH, USA) as instructed by the manufacturer. Filters from the two corresponding $30 \mathrm{~cm}$ sections of the duplicate ice cores were combined before DNA extraction in order to ensure sufficient DNA yield. DNA concentration was quantified fluorometrically with SYBR Green (Life Technologies) in a NanoDrop3300 Fluorometer (Thermo Fisher Scientific, Waltham, MA, USA) according to the manufacturer's instructions. DNA extraction products from sections from the same core were combined in equal concentrations before amplification and sequencing. The $\mathrm{V} 1-\mathrm{V} 3$ regions of the bacterial 16S rRNA gene were PCR amplified in triplicate using 27 F-518R primers (Supplementary Table S2), mixed in equal concentrations and purified using Agencourt AMPure beads (Agencourt Bioscience Corporation, MA, USA) as previously described (Hatam et al., 2014). Molecular Research LP (Shallowater, TX, USA) sequenced the resulting products using FLX-Titanium amplicon pyrosequencing on the the Genome Sequencer FLX System (Roche, Branford, CT, USA) as previously described (Dowd et al., 2008; Hatam et al., 2014). A list of all primers and barcodes is provided in Supplementary Table S2.

Pre-processing and quality control of raw sequences All pre-processing and sequence quality control steps were performed using Mothur v. 1.33.3 following the Mothur 454 SOP for sff \& flow files (http://www. mothur.org/wiki/454_SOP access date 13 August 2014) (Schloss et al., 2009). In brief, raw flowgram data were used to discard sequences not in the range of 360-720 flows, as recommended (Quince et al., 2011). Noise reduction was performed using the Mothur implementation of the PyroNoise algorithm which corrects PCR- and pyrosequencing-generated errors (Quince et al., 2009; Schloss et al., 2011). Sequences shorter than 200 base pairs (bp) or those containing primer/barcode mismatches or homopolymers longer than $8 \mathrm{bp}$ were discarded. The remaining sequences, which were all 250-350 bp long, were aligned against the SILVA reference data set (version 110), and then pre-clustered for further noise reduction as recommended (Pruesse et al., 2007; Huse et al., 2010). Chimeras were detected and removed using the Mothur implementation of UCHIME (Edgar et al., 2011). Operational taxonomic units (OTUs) were assigned using the averageneighbor clustering algorithm for an OTU definition of $97 \%$ similarity. Global singleton OTUs, represented as just one sequence in the data set, were excluded; and the remaining OTUs were assigned to taxonomic classification using the Mothur implementation of the Ribosomal Database Project classifier (train set 10) with a $60 \%$ confidence threshold (RDP; http://rdp. cme.msu.edu/). Using this threshold, we were able to classify $75 \%, 85 \%$ and $82 \%$ of the sequences to below the domain bacteria and $37 \%, 51 \%$ and $18 \%$ of the sequences to the genus level in FYI, MYI and SW, respectively. On basis of this classification, sequences of mitochondrial, chloroplast, eukaryotic or unknown origin (sequences that could not be classified at the domain level) were removed from the data set. Preanalysis data clean-up processes eliminated $\sim 30 \%$ of the total raw sequences. The sequences were subsampled to the smallest library size $(n=1100$ for individual samples, $n=8000$ for merged FYI, MYI and SW groups) to allow identical sampling efforts for each sample before further analyses (Gihring et al., 2012). Sequences are available from the National Center for Biotechnology Information Sequence Read Archive under bioproject PRJNA288609 biosamples SAMN04334613-SAMN04334626, SRA accession SRP067418.

\section{Community analysis}

Mothur v. 1.33.3 was used for all community analyses and statistics as previously described (Schloss et al., 2009). Alpha diversity was estimated using the Chao1 and ACE non-parametric richness estimators, reciprocal Simpson's diversity index (invsimpson) and Shannon diversity index (Shannon, 1947; Simpson, 1949; Chao, 1984; Chao and Shen, 2003). Community evenness was estimated using HEIP (Heip, 1974). Coverage was calculated as the ratio between observed and estimated richness. On the basis of this calculation, all our samples showed $\sim 90 \%$ coverage, which indicates a good sampling effort (Figure 1). Furthermore, rarefaction curves for both individual and merged samples (that is, 8000 and 1100 sequences) approached an asymptote, further indicating a high level of coverage of the bacterial community diversity (Supplementary Figures S2A and B). Yue and Clayton's theta measure of dissimilarity $\left(\theta_{\mathrm{yc}}\right)$ and Jaccard's dissimilarity coefficient (J-class) were used to compare the composition (that is, dissimilarity of communities based on OTU relative proportion) and membership (that is, similarity of communities based on shared OTUs), respectively, of the different communities in an OTU-based, phylogenyindependent manner (Jaccard, 1912; Yue and Clayton, 2005). PCoA (principal coordinates analysis) was used to ordinate the different samples in multidimensional space, based on the distance matrices generated by $\theta_{\mathrm{yc}}$ and J-class. The non-parametric analysis of 
2546
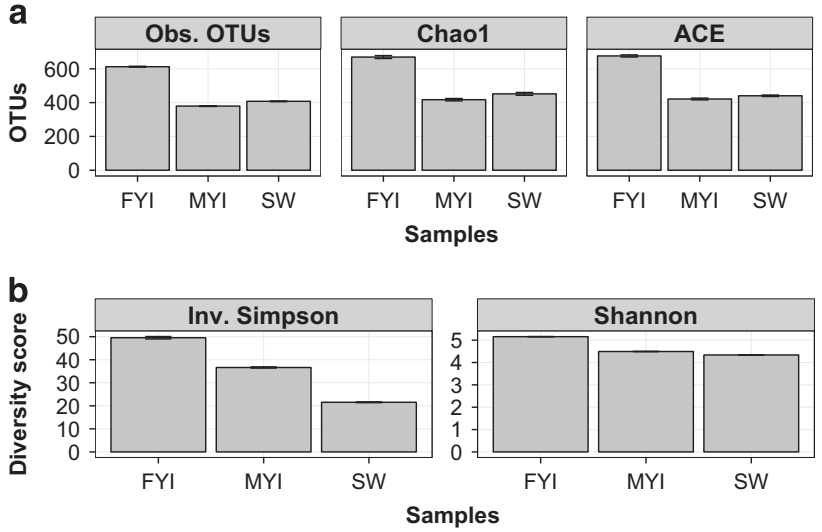

Figure 1 (a) Richness (observed and predicted) and (b) diversity measurements for pooled FYI, MYI and SW samples $(n=3)$. OTU definition set at $97 \%$ sequence similarity, values \pm s.e.m.

molecular variance (AMOVA) was used to test the significance of the grouping based on the PCoA ordination: statistical significance of grouping was tested for $P \leqslant 0.05$ with Bonferroni correction according to the number of groups tested (Excoffier et al., 1992; Anderson, 2001; Martin, 2002). Mothur v 1.33.3 was used to visualize shared observed richness using Venn diagrams (Schloss et al., 2009). Mathlab v 7.13 was used to plot PCoAs. A neighbor joining phylogenetic tree of representative OTU sequences was constructed for core members of each sample type, that is OTUs found in all MYI, in all SW or in all FYI samples using MAFFT version 7 (http://mafft.cbrc.jp/ alignment/server/). Tree visualization and the addition of OTU abundance to each branch were done in $\mathrm{R}$ version 3.1.1 (http://www.r-project.org) with the phyloseq package (McMurdie and Holmes, 2013). Sequences of these OTUs were deposited to the NCBI sequence repository under accession numbers (KU308473-KU3085).

Of the OTUs that were part of the core membership, those found exclusively in all MYI were further identified using the nucleotide BLAST search tool (BLASTn) against the NCBI non-redundant (nr) database with the exclusion of model and uncultured organisms to identify the closest cultured relative. On the basis of this classification, the hypothetical ecological function of the OTU was assumed. We also used a similar BLASTn search but including uncultured bacteria to identify the environments the most similar sequences originated from. For both BLASTn searches, a maximum expect value of $e^{-90}$ was accepted.

\section{Results}

Salinity profiles for the sites in this study were done in 10-cm intervals and were taken from Lange et al. (2015) (Supplementary Figure S1). For each site, mean Chla concentrations as well as snow and ice depth, previously reported by Lange et al. (2015), are also reported in Supplementary Table S1. No statistical differences in these parameters were found between FYI and MYI (Lange et al., 2015).

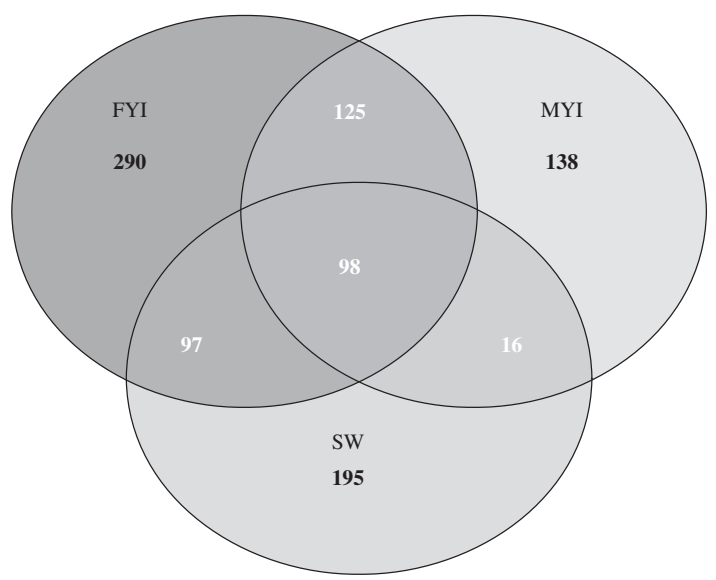

Figure 2 Shared OTUs. Venn diagram of shared OTUs between MYI, FYI and SW. OTU definition set at $97 \%$ sequence similarity.

Communities from FYI have higher taxon richness and diversity than MYI

Taxon richness in FYI (observed and estimated; Figure 1a) and diversity (Figure 1b) in FYI were significantly higher than for MYI and SW (repeated measure ANOVA, $P<0.05$ ). Although observed and estimated OTU richness for bacterial communities from MYI were lowest of all three sample types, overall diversity was higher for MYI than for SW (Figure 1b). The discrepancy between OTU richness and overall diversity is because OTUs were more unevenly distributed in SW (HEIP evenness 0.186) than FYI (HEIP evenness 0.233) or MYI (HEIP evenness 0.282).

FYI bacterial communities have unique, MYI-like and SW-like components

Communities from all sample types showed a high number of OTUs not found in the other sample types (that is, unique OTUs); however, FYI and SW communities had more unique OTUs $(47.5 \%$ and $48 \%$, respectively) than MYI communities (36\% unique OTUs) (Figure 2). MYI bacterial communities shared twice the fraction of OTUs with FYI (59\%) as with SW (30\%) (Figure 2); FYI bacterial communities share similar proportions of their OTUs with MYI and SW communities (36\% and 32\%, respectively; Figure 2). Furthermore, $33 \%$ of OTUs from MYI are shared exclusively with FYI, which is eight times higher than the fraction MYI shares exclusively with SW (Figure 2). This differential stands in contrast to communities from FYI, which share similar fractions of their OTUs exclusively with both MYI and SW (20\% and 16\%, respectively; Figure 2). Thus, FYI and SW bacterial communities are more similar to each other than MYI and SW.

Composition of major class-level groups shows minimal differences between ice types or sea water

The majority of OTUs from both ice types could be classified into class-level taxonomic groups; those that 
were not are represented at the phylum level (Figure 3). Most of the class-/phylum-level groups were similar between the two ice types (Figure 3). The predominant class-level groups in both FYI and MYI communities were Alphaproteobacteria $(\sim 10 \%$ in FYI and $\sim 15 \%$ in MYI), Gammaproteobacteria ( 15\% in both sample types), Flavobacteria ( 10\% in both sample types) and the class-level group Actinobacteria within the phylum Actinobacteria $(\sim 10 \%$ in both sample types) (Figure 3). Class-level groups representing less than $1 \%$ of the total sequences were grouped together as 'Other'. The class-level group Opitutae represented a fraction greater than $1 \%$ of the sequences only in MYI communities (Figure 3).

At the class/phylum level, ice communities were minimally different from SW communities. Within the major class-/phylum-level groups, only sequences closely related to the class Sphingobacteria and unclassified Bacteroidetes had relative abundance greater than $1 \%$ in ice and lower than $1 \%$ in SW (Figure 3). Sequences classified as closely related to the phylum-level group Firmicutes appeared only in SW (albeit with relative abundance lower than 1\%; data not shown) and not in ice.

\section{MYI and FYI have distinct membership, but not composition}

Despite the high similarity in the composition of FYI, MYI and SW bacterial communities at higher taxonomic levels, examination of the community membership and compositions at finer scales show significant differences. The J-class index of dissimilarities between memberships of different communities showed clustering of the samples to three statistically significant groups (max pair-wise $P$-value $P<0.004$ ) based on sample type (that is, FYI, MYI and SW; Figure 4a). An alternate dissimilarity measure, Yue and Clayton's $\theta$ measure of dissimilarity $\left(\theta_{\mathrm{yc}}\right)$, which accounts for relative abundance of taxa and

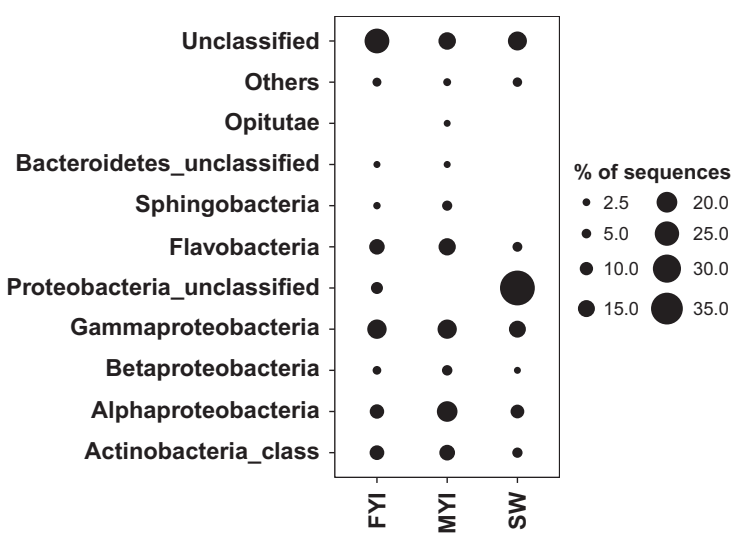

Figure 3 Class-level composition of the three sample types. Proportion is represented as percent of total sequences per sample type. Classes that amounted to less than $1 \%$ of the total sequences per sample type were pooled as 'Others'. 'Unclassified' sequences could not be classified below the level of domain 'Bacteria'. If classifiable below the domain bacteria, then OTUs that cannot be classified to the class level are identified as phylum-level group_unclassified. thus measures composition, also showed three statistically significant groups ( $\max$ pair-wise $P$-value $P<0.01$; Figure 4b); however, the membership of these groups was not determined by sample type. although the SW and MYI mostly maintained their grouping, FYI samples grouped with either SW or MYI samples: two of the FYI samples formed a cluster with four of the five MYI samples; one FYI sample grouped with the SW samples, and two FYI samples grouped with the remaining MYI sample. The difference between clustering by membership and composition indicates that the FYI bacterial communities share mainly low abundance OTUs, while MYI and SW share both low and high abundance OTUs.
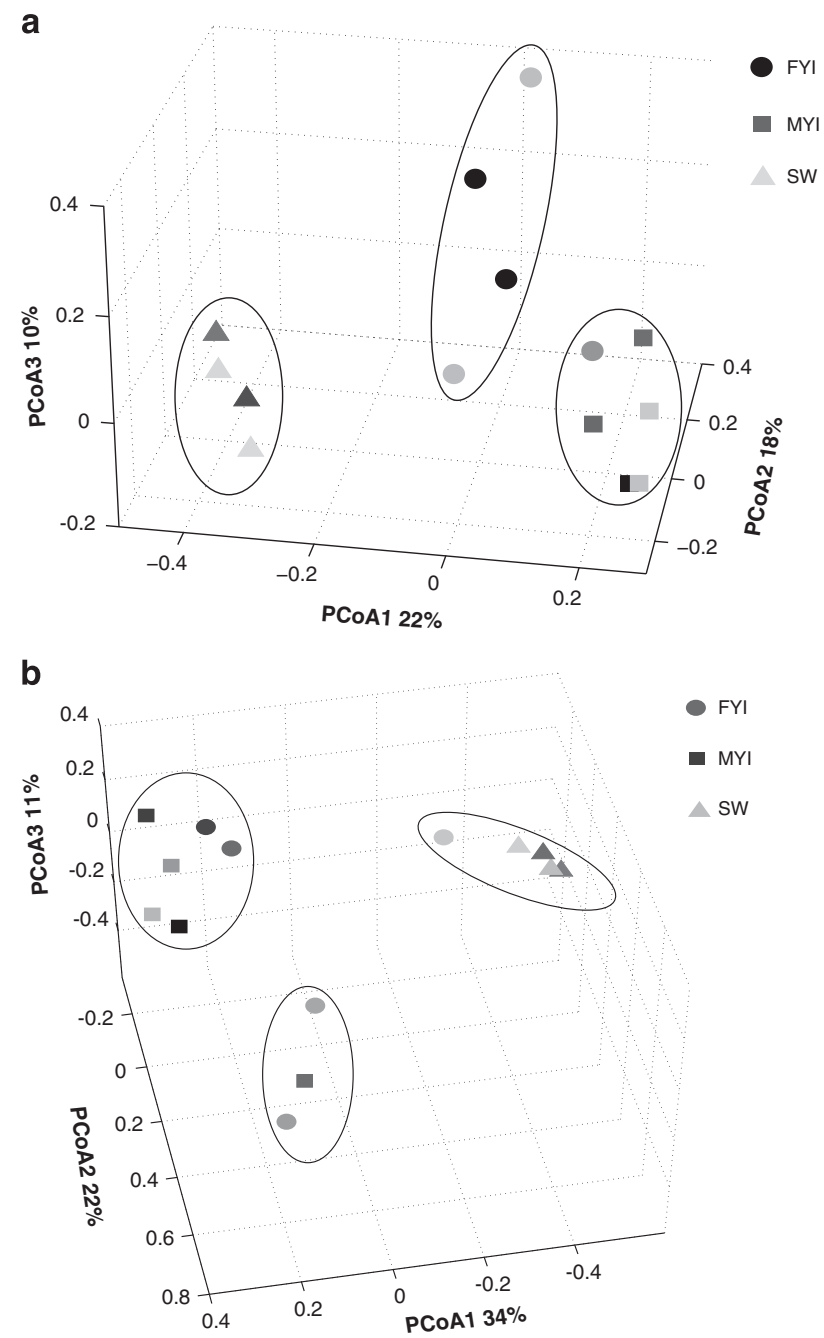

Figure 4 OTU membership and composition of communities from the different samples: Clustering of the communities based on (a) membership (J-class dissimilarity index; $r^{2}=0.82$; AMOVA scores $\mathrm{MvF} \mathrm{F}_{(1,9)} 2.78 P<0.001, \mathrm{MvSW} \mathrm{F}_{(1,6)} 1.77 P<0.002$, FvSW $\left.\mathrm{F}_{(1,9)} 1.42 P<0.004\right)$ and $(\mathbf{b})$ composition $\left(\theta_{\mathrm{yc}}\right.$ dissimilarity index; $r^{2}=0.89$; AMOVA scores MvF $\mathrm{F}_{(1,6)} 8.3 P<0.01$, MvSW $\mathrm{F}_{(1,10)} 9.24$ $\left.P<0.001, F_{v} S W F_{(1,8)} 4.14 P<0.01\right)$. Statistically significant clustering based on AMOVA is circled in black. OTU definition set at $97 \%$ sequence similarity; sequencing depth was normalized to 1100 reads. ' $\mathrm{F}$ ' = first-year ice, ' $\mathrm{M}$ ' = multi-year ice, 'S' = surface sea water; numbers represent year sampled; ' $A$ ' and ' $\mathrm{B}$ ' = sites sampled/year. 
Communities from MYI have a broader core membership than FYI

To further investigate the core OTUs of the bacterial communities from different sample types, we compared the number of OTUs that are found in all MYI samples, all SW samples and those that are found in all FYI samples (Figure 5). Note that these OTUs are not necessarily exclusive to one sample type, but are found in all samples of that type. All MYI samples shared 20 OTUs, representing $\sim 5 \%$ of the observed OTUs in MYI; these core MYI OTUs accounted for an average of $\sim 25 \%$ of the total sequences from MYI samples (Figure 5). Similarly, all SW samples shared
34 OTUs, representing $\sim 8 \%$ of the observed OTUs for SW; these core SW OTUs accounted for an average of $\sim 55 \%$ of the total sequences from SW samples (Figure 5). In contrast, all FYI samples shared only seven OTUs, representing $\sim 1 \%$ of observed OTUs for FYI; these core FYI OTUs accounted for $11 \%$ of the total sequences from FYI samples (Figure 5). Furthermore, of those seven core FYI OTUs, four were also shared with all of the MYI samples and two with all of the SW samples, meaning only one OTU was shared between all FYI samples exclusively. In contrast, many more OTUs were shared between all MYI samples exclusively or

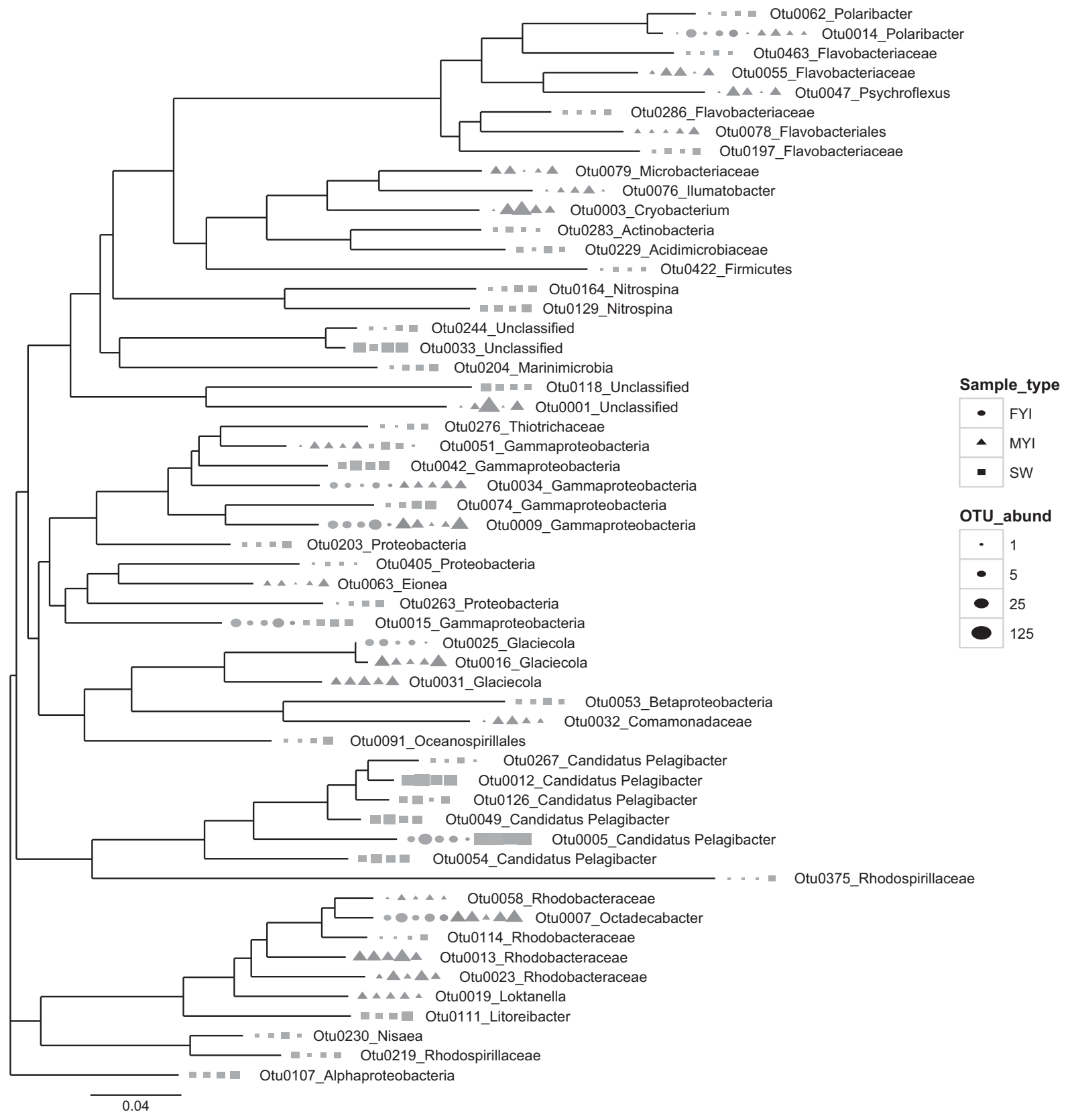

Figure 5 Neighbor joining phylogenetic tree showing relationship of OTUs found in all MYI samples, all FYI samples or both. OTU definition set at 97\% sequence similarity; shapes correspond to ice type (FYI or MYI); symbol size corresponds to OTU abundance. Sample naming as in Figure 4. 
all SW samples exclusively (15 and 32, respectively; Figure 5, Supplementary Figure S3).

The closest relatives of the 15 OTUs exclusive to all MYI samples with NCBI BLAST were found primarily in cold environments (marine, freshwater or terrestrial) (Supplementary Table S3). Four of these OTUs belong to the Rhodobacteraceae family with two of the four in the genera Loktanella and Roseobacter. Both of these genera are known to have a role in the degradation of dimethylsulfoniopropionate originating from marine algae (Gonzalez et al., 1999; Moran et al., 2007). Other OTUs were members of the genus Glacicola (Supplementary Table S3) known for their role in hydrolyzing complex organic carbon molecules such as cellulose and chitin originating from algae (Qin et al., 2014). An OTU related to Psychroflexus torques, which is known to associate with ice algae (Bowman et al., 1998) and may oxidize dimethylsulfoniopropionate, was also exclusive to the core MYI group. One of the OTUs was closely related to Glacicola nitratireducens (Supplementary Table S3), which is involved in the nitrogen cycle through denitrification (Qin et al., 2014). The fact that these Glacicola sequences are found in high abundance in all MYI samples may explain a previous observation that denitrification occurs much more strongly in MYI than in FYI (Rysgaard et al., 2008). Psychroflexus torques may also contribute to the primary productivity of sea ice via proteorodopsin-mediated carbon fixation and the secretion of extracellular polysaccharides (Feng et al., 2013). Taken together, the groups found exclusively in the MYI core community are cold adapted organisms that consume algal products and transform nitrogen and carbon within the ice.

\section{Discussion}

Class-level taxonomic groups from the bacterial communities in our sea ice samples are similar to groups previously shown to dominate sea ice in both polar and sub-polar seas. Most of the OTUs that were present in all sea ice samples in our study were most similar to previously identified sea ice bacteria from the Arctic, Antarctic and the Baltic Sea (Figure 5) (Junge et al., 2001; Petri and Imhoff, 2001; Brinkmeyer et al., 2003; Bowman et al., 2012; Eronen-Rasimus et al., 2014; Han et al., 2014; Hatam et al., 2014). Furthermore, MYI bacterial communities from the sites we sampled had comparable OTU richness and diversity values to those shown in previous studies of sea ice bacterial communities (Bowman et al., 2012; Hatam et al., 2014). It is worth noting that communities from FYI showed the highest OTU richness and overall diversity by a large margin. This is the first study to use high throughput sequencing of $16 \mathrm{~S}$ rRNA genes with Arctic FYI bacterial communities; therefore, there is no point of reference to compare our values with that geographical location. However, our diversity indices were comparable to those recently published for Antarctic seasonal pack ice (Torstensson et al., 2015).
Although our study had a modest geographic scope, focusing exclusively on land fast ice from the Lincoln Sea, our richness and diversity trends were similar to studies conducted in summer pack ice (Bowman et al., 2012; Han et al., 2014). Furthermore, the OTU composition from our ice samples was similar to these studies at the class level and lower (if the sequences could be resolved to lower taxonomic levels). Thus, although land fast ice is more affected by riverine input and sediment upwelling than pack ice (Wadhams, 2000), our findings may be broadly applicable to both types of ice and the Arctic as a whole.

If we define 'core community' as OTUs found in all samples of a sample type, then the FYI core community is not robust, that is, there are few OTUs shared among all FYI and they represent a small fraction of the total FYI sequences. Therefore, the ancillary community, that is, those OTUs found in some but not in all of the FYI samples determine the similarity to other sample types based on community composition. In other words, based on composition, FYI does not have a clear core community; rather, it is a composite community that is more similar to either MYI or SW.

In contrast, our results show that bacterial communities from MYI have low sample-to-sample variability in both community membership and composition. Sample grouping was independent of site and year of sampling, indicating a high level of stability of these communities. Their common structure may be the consequence of selection processes resulting from formation and maturation of MYI, including transition from water to ice, freeze and thaw cycles, flushing of the ice with melt water, brine drainage and the formation of different layers within the ice depending on the original water source (Mock and Thomas, 2005). The low variability and high stability of the MYI bacterial communities is further supported by the high number of OTUs shared by all MYI samples as compared with the low number of OTUs shared by all FYI samples. However, larger sampling efforts across the Arctic are needed to determine whether this observation can be generalized.

One possible explanation for the clustering of FYI based on membership is that the less abundant, unique (that is, found in at least one FYI sample but not in other sample types) OTUs in FYI are transient and not well adapted to life in sea ice, and thus are not found in MYI. These unique OTUs could originate from non-sea water sources such as sediment or the aeolian deposition of particles (Bunch and Harland, 1990; Reimnitz et al., 1992; Laurion et al., 1995), a possibility supported by the presence of members of the genera Arthrobacter and Solirubrobacter and the Phylum Chloroflexie. These taxa are primarily found in terrestrial and sediment environments and are only found in the FYI samples, not MYI or SW. Alternatively, these OTUs unique to FYI could be present at very low abundance in sea water, but are preferentially scavenged during FYI formation 
(Garrison et al., 1983; Gradinger and Ikävalko, 1998; Weissenberger and Grossmann, 1998). In this case, bacterial communities from FYI samples group with either SW or MYI based on composition because the most abundant OTUs either originate from SW or are well adapted to survival in sea ice conditions, and are therefore abundant in MYI as well. Thus, the transition from MYI to FYI will result in a more variable and unstable microbial community in Arctic sea ice.

The core OTUs for the MYI bacterial communities are primarily specialized psychrophiles, with relatives found in both cold marine sediments and cold freshwater environments (Supplementary Table S3). Prominent members of the core MYI OTUs seem to be specialized in exploiting the ice algal bloom via the oxidation of dimethylsulfoniopropionate or the breakdown of complex organic carbon molecules synthesized by ice algae (Supplementary Table S3). We interpret these findings to indicate an MYI core community acclimated to cold environments and ready to exploit the ice algal bloom, with implications for the nitrogen, sulfur and carbon cycles. Thus, these biogeochemical cycles might be impacted with the disappearance of MYI and its stable community. Such losses may lead to changes in nutrient dynamics in sea ice and the Arctic Ocean, such as decreased denitrification in the ice and increased export of organic carbon from the ice (due to lower efficiency of carbon utilization), which in turn may increase nutrient export to the water column and sediments. However, it is unclear whether the increased variability of the FYI community composition might mask such impacts.

\section{Conclusions}

To the best of our knowledge, this is the first study comparing the composition of bacterial communities from MYI and FYI using high throughput sequencing. Though of modest scale both geographically and seasonally, our data suggest two distinct phases in the development of bacterial community composition in the sea ice cover of the Lincoln Sea. The first phase is a transient FYI community, with distinct membership but not composition that may reflect the stochastic incorporation of bacteria into the growing ice. The second phase is a mature MYI community with a broad base of shared members found in high relative abundance. As the Arctic warms and MYI transitions to FYI, our results indicate that there will be a shift from a highly stable sea ice bacterial community toward one that is more variable in its composition. Due to the high degree of functional redundancy found in bacterial communities, it is unclear what effect the shift in community structure will have on the ecology of the Arctic Ocean. However, we predict that the variability and instability at the compositional level translates to similar variability and instability at the functional level and may decrease the ability of these communities to adapt to the effects of environmental disturbance and may change nutrient dynamics in the Arctic Ocean.

\section{Conflict of Interest}

The authors declare no conflict of interest.

\section{Acknowledgements}

BDL and $\mathrm{CH}$ were supported by the Natural Science and Engineering Research Council of Canada (NSERC) Discovery Grant program and the Polar Continental Shelf Program (PCSP). $\mathrm{CH}$ was an Alberta InnovatesTechnology Futures Fellow. IH, BL and JB were supported by the Northern Scientific Training Program (NSTP) and Circumpolar-Boreal Arctic Research (C-BAR) programs. We would like to thank and acknowledge the PCSP and CFS Alert staff for their hospitality and logistical support while in the field. We would also like to acknowledge the editor and two anonymous reviewers for their input which helped improve this manuscript.

\section{References}

Anderson MJ. (2001). A new method for non-parametric multivariate analysis of variance. Austral Ecol 26: 32-46.

Arrigo KR, Perovich DK, Pickart RS, Brown ZW, van Dijken GL, Lowry KE et al. (2012). Massive phytoplankton blooms under Arctic sea ice. Science 336: 1408.

Bowman JP, McCammon SA, Lewis T, Skerratt JH, Brown JL, Nichols DS et al. (1998). Psychroflexus torquis gen. nov., sp. nov. a psychrophilic species from Antarctic sea ice, and reclassification of Flavobacterium gondwanense (Dobson et al. 1993) as Psychroflexus gondwanense gen. nov., comb. nov. Microbiology 144: 1601-1609.

Bowman JS, Rasmussen S, Blom N, Deming JW, Rysgaard S, Sicheritz-Ponten T. (2012). Microbial community structure of Arctic multiyear sea ice and surface seawater by 454 sequencing of the 16S RNA gene. ISME J 6: 11-20.

Boé J, Hall A, Qu X. (2009). September sea-ice cover in the Arctic Ocean projected to vanish by 2100. Nat Geosci 2: 341-343.

Brinkmeyer R, Knittel K, Jürgens J, Weyland H, Amann R, Helmke E. (2003). Diversity and structure of bacterial communities in Arctic versus Antarctic pack ice. Appl Environ Microbiol 69: 6610-6619.

Bunch JN, Harland RC. (1990). Bacterial production in the bottom surface of sea ice in the Canadian subarctic. Can J Fish Aquat Sci 47: 1986-1995.

Chao A. (1984). Nonparametric estimation of the number of classes in a population. Scand J Stat 11: 265-270.

Chao A, Shen T. (2003). Nonparametric estimation of Shannon's index of diversity when there are unseen species in sample. Environ Ecol Stat 10: 429-443.

Deming JW. (2007). Life in ice formations at very cold temperatures. In: Gerday C, Glansdorff N (eds), Physiology and Biochemistry of Extremophiles. ASM Press: Washington, DC, USA, pp 133-145.

Dowd S, Sun Y, Secor P, Rhoads D, Wolcott B, James G et al. (2008). Survey of bacterial diversity in chronic wounds using Pyrosequencing, DGGE, and full ribosome shotgun sequencing. BMC Microbiol 8: 43. 
Edgar RC, Haas BJ, Clemente JC, Quince C, Knight R. (2011). UCHIME improves sensitivity and speed of chimera detection. Bioinformatics 27: 2194-2200.

Eicken H. (2008). From the microscopic, to the nacroscopic, to the regional scale: growth, microstructure and properties of sea ice. In: Thomas DN, Dieckmann GS (Eds), Sea Ice: An Introduction to its Physics, Chemistry, Biology and Geology. Blackwell Science Ltd: London, UK, pp 22-81.

Eronen-Rasimus E, Lyra C, Rintala JM, Jurgens K, Ikonen V, Kaartokallio H. (2014). Ice formation and growth shape bacterial community structure in Baltic Sea drift ice. FEMS Microbiol Ecol 91: 1-13.

Excoffier L, Smouse PE, Quattro JM. (1992). Analysis of molecular variance inferred from metric distances among DNA haplotypes: application to human mitochondrial DNA restriction data. Genetics 131: 479-491.

Feng S, Powell SM, Wilson R, Bowman JP. (2013). Light-stimulated growth of proteorhodopsin-bearing sea-ice psychrophile Psychroflexus torquis is salinity dependent. ISME J 7: 2206-2213.

Garrison DL, Ackley SF, Buck KR. (1983). A physical mechanism for establishing algal populations in frazil ice. Nature 306: 363-365.

Gihring TM, Green SJ, Schadt CW. (2012). Massively parallel rRNA gene sequencing exacerbates the potential for biased community diversity comparisons due to variable library sizes. Environ Microbiol 14: 285-290.

Gonzalez JM, Kiene RP, Moran MA. (1999). Transformation of sulfur compounds by an abundant lineage of marine bacteria in the alpha-subclass of the class Proteobacteria. Appl Environ Microbiol 65: 3810-3819.

Gosselin M, Levasseur M, Wheeler PA, Horner RA, Booth BC. (1997). New measurements of phytoplankton and ice algal production in the Arctic Ocean. Deep Sea Res Pt II 44: 1623-1644.

Gradinger R, Ikävalko J. (1998). Organism incorporation into newly forming Arctic sea ice in the Greenland Sea. J Plankton Res 20: 871-886.

Haas C, Hendricks S, Doble M. (2006). Comparison of the sea-ice thickness distribution in the Lincoln Sea and adjacent Arctic Ocean in 2004 and 2005. Ann Glaciol 44: 247-252.

Haas C, Hendricks S, Eicken H, Herber A. (2010). Synoptic airborne thickness surveys reveal state of Arctic sea ice cover. Geophys Res Lett; e-pub ahead of print 14 May 2010; doi:10.1029/2010GL042652.

Han D, Kang I, Ha HK, Kim HC, Kim O, Lee BY et al. (2014). Bacterial communities of surface mixed layer in the Pacific sector of the Western Arctic ocean during sea-ice melting. PLOS ONE 9: e86887.

Hatam I, Charchuk R, Lange B, Beckers J, Haas C, Lanoil B. (2014). Distinct bacterial assemblages reside at different depths in Arctic multiyear sea ice. FEMS Microbiol Ecol 90: 115-125.

Heip C. (1974). A new index measuring evenness. J Mar Biol Assoc UK 54: 555-557.

Huse SM, Welch DM, Morrison HG, Sogin ML. (2010). Ironing out the wrinkles in the rare biosphere through improved OTU clustering. Environ Microbiol 12: 1889-1898.

Jaccard P. (1912). The distribution of the flora in the alpine zone. New Phytol 11: 37-50.

Junge K, Eicken H, Deming JW. (2004). Bacterial activity at -2 to $-20^{\circ} \mathrm{C}$ in Arctic Wintertime sea ice. Appl Environ Microbiol 70: 550-557.
Junge K, Eicken H, Swanson BD, Deming JW. (2006). Bacterial incorporation of leucine into protein down to -20 degrees $\mathrm{C}$ with evidence for potential activity in subeutectic saline ice formations. Cryobiology 52: 417-429.

Junge K, Krembs C, Deming J, Stierler A, Eicken H. (2001). A microscopic approach to investigate bacteria under in situ conditions in sea-ice samples. Ann Glaciol 33: 304-310.

Kaartokallio H, Laamanen M, Sivonen K. (2005). Responses of Baltic sea ice and open-water natural bacterial communities to salinity change. Appl Environ Microbiol 71: 4364-4371.

Kaartokallio H, Tuomainen J, Kuosa H, Kuparinen J, Martikainen PJ, Servomaa K. (2008). Succession of natural sea-ice bacterial communities in the Baltic Sea fast ice. Polar Biol 31: 783-793.

Lange AB, Michel C, Beckers JF, Casey JA, Flores H, Hatam I et al. (2015). Comparing springtime ice-algal chlorophyll a and physical properties of multi-year and first-year sea ice from the Lincoln sea. PLOS ONE 10: e0122418.

Laurion I, Demers S, Vézina F. (1995). The microbial food web associated with the ice algal assemblage: biomass and bacterivory of nanoflagellate protozoans in Resolute Passage (High Canadian Arctic). Mar Ecol Prog Ser 120: 77-87.

Lowry KE, van Dijken GL, Arrigo KR. (2014). Evidence of under-ice phytoplankton blooms in the Chukchi Sea from 1998 to 2012. Deep Sea Res Pt II 105: 105-117.

Martin AP. (2002). Phylogenetic approaches for describing and comparing the diversity of microbial communities. Appl Environ Microbiol 68: 3673-3682.

Maslanik J, Stroeve J, Fowler C, Emery W. (2011). Distribution and trends in Arctic sea ice age through spring 2011. Geophys Res Lett 38: L13502.

McMinn A, Hegseth E. (2007). Sea ice primary productivity in the northern Barents Sea, spring 2004. Polar Biol 30: 289-294.

McMinn A, Ryan K, Ralph P, Pankowski A. (2007). Spring sea ice photosynthesis, primary productivity and biomass distribution in eastern Antarctica, 2002-2004. Mar Biol 151: 985-995.

McMurdie PJ, Holmes S. (2013). phyloseq: an R package for reproducible interactive analysis and graphics of microbiome census data. PLOS ONE 8: e61217.

Mock T, Thomas DN. (2005). Recent advances in sea-ice microbiology. Environ Microbiol 7: 605-619.

Moran MA, Belas R, Schell MA, González JM, Sun F, Sun S et al. (2007). Ecological genomics of marine Roseobacters. Appl Environ Microbiol 73: 4559-4569.

Overland JE, Francis JA, Hanna E, Wang M. (2012). The recent shift in early summer Arctic atmospheric circulation. Geophys Res Lett; e-pub ahead of print 10 October 2012; doi:10.1029/2012GL053268.

Petri R, Imhoff J. (2001). Genetic analysis of sea-ice bacterial communities of the Western Baltic Sea using an improved double gradient method. Polar Biol 24: 252-257.

Poltermann M. (2001). Arctic sea ice as feeding ground for amphipods - food sources and strategies. Polar Biol 24: 89-96.

Post E, Bhatt US, Bitz CM, Brodie JF, Fulton TL, Hebblewhite $\mathrm{M}$ et al. (2013). Ecological consequences of sea-ice decline. Science 341: 519-524.

Pruesse E, Quast C, Knittel K, Fuchs BM, Ludwig W, Peplies J et al. (2007). SILVA: a comprehensive online resource for quality checked and aligned ribosomal RNA sequence data compatible with ARB. Nucleic Acids Res 35: 7188-7196. 
Qin Q, Xie B, Yu Y, Shu Y, Rong J, Zhang Y et al. (2014). Comparative genomics of the marine bacterial genus Glaciecola reveals the high degree of genomic diversity and genomic characteristic for cold adaptation. Environ Microbiol 16: 1642-1653.

Quince C, Lanzen A, Curtis TP, Davenport RJ, Hall N, Head IM et al. (2009). Accurate determination of microbial diversity from 454 pyrosequencing data. Nat Methods 6: 639-641.

Quince C, Lanzen A, Davenport RJ, Turnbaugh PJ. (2011). Removing noise from pyrosequenced amplicons. $B M C$ Bioinformatics 12: 38.

Reimnitz E, Marincovich Jr L, McCormick M, Briggs WM. (1992). Suspension freezing of bottom sediment and biota in the Northwest passage and implications for Arctic Ocean sedimentation. Can J Earth Sci 29: 693-703.

Riedel A, Michel C, Gosselin M, LeBlanc B. (2008). Winterspring dynamics in sea-ice carbon cycling in the coastal Arctic Ocean. J Mar Syst 74: 918-932.

Rysgaard S, Glud R, Sejr M, Blicher M, Stahl H. (2008). Denitrification activity and oxygen dynamics in Arctic sea ice. Polar Biol 31: 527-537.

Rysgaard S, Glud RN. (2004). Anaerobic N2 production in Arctic sea ice. Limnol Oceanogr 49: 86-94.

Schloss PD, Gevers D, Westcott SL. (2011). Reducing the effects of PCR amplification and sequencing artifacts on 16S rRNA-based studies. PLoS One 6: e27310.

Schloss PD, Westcott SL, Ryabin T, Hall JR, Hartmann M, Hollister EB et al. (2009). Introducing mothur: Opensource, platform-independent, community-supported software for describing and comparing microbial communities. Appl Environ Microbiol 75: 7537-7541.

Serreze MC, Holland MM, Stroeve J. (2007). Perspectives on the Arctic's shrinking sea-ice cover. Science 315: 1533-1536.

Shannon CE. (1947). A mathematical theory of communication. Bell Syst Tech J 27: 379-423.

Simpson EH. (1949). Measurement of diversity. Nature 163: 688.

Torstensson A, Dinasquet J, Chierici M, Fransson A, Riemann L, Wulff A. (2015). Physicochemical control of bacterial and protist community composition and diversity in Antarctic sea ice. Environ Microbiol 17: 3869-3881.

Wadhams P. (2000). Ice in the Ocean. Gordon and Breach Science Publishers: London, UK.

Wassmann P, Reigstad M. (2011). Future Arctic Ocean seasonal ice zones and implications for pelagic-benthic coupling. Oceanography 24: 220-231.

Weissenberger J, Grossmann S. (1998). Experimental formation of sea ice: importance of water circulation and wave action for incorporation of phytoplankton and bacteria. Polar Biol 20: 178-188.

Wing S, McLeod R, Leichter J, Frew R, Lamare M. (2012). Sea ice microbial production supports Ross Sea benthic communities: influence of a small but stable subsidy. Ecology 93: 314-323.

Yue JC, Clayton MK. (2005). A similarity measure based on species proportions. Commun Stat Theory Methods 34: 2123-2131.

Supplementary Information accompanies this paper on The ISME Journal website (http://www.nature.com/ismej) 